\title{
A posição do negro no interior do capitalismo.
}

\section{Douglas Rodrigues Barros ${ }^{1}$}

Muito já se falou do negro e sua posição na sociedade do consumo. Por todos os lados, entretanto, parece que o negro enquanto tal só pode ser abordado em contraposição direta ao sujeito branco. A discussão, desse modo, fica em torno do sujeito detentor de direitos e privilégios (branco e macho) e do sub-sujeito (negro, mulher, etc.,) que fora podado ou tem menos acesso aos benefícios do consumo. Os movimentos sociais, principalmente aqueles que lutam pelo reconhecimento da negritude, se veem, com isso, limitados às pautas de inclusão que muitas vezes, ao invés de promover uma real emancipação, promovem uma adequação ao status quo.

Algumas hipóteses indicam que as raízes desse problema se encontram na própria constituição da modernidade e seus pressupostos ideológicos. Pressupostos que se acaso não forem colocados em xeque, muitas vezes, tornam-se um desserviço para os negros e para todos aqueles que efetivamente lutam por uma sociedade emancipada. $\mathrm{O}$ Esclarecimento e sua ideologia parecem assim constituir, em termos da práxis política, o grande empecilho para uma proposta verdadeiramente emancipatória que esteja para além do capital. É bom que fique claro; a constituição da modernidade é o que baseia o Esclarecimento e não o contrário. Aqui chamamos de constituição da modernidade o desenvolvimento do sistema produtor de mercadoria que engendrou a divisão social do trabalho e das atividades cientificas. Momento em que se instaura uma cisão profunda entre a objetividade e a subjetividade que fora captada nos principais romances e obras artísticas.

Nesse sentido, os primeiros a verem os problemas implícitos no desdobramento dos ideais que acompanhavam o iluminismo foram Adorno e Horkheimer na célebre Dialética do Esclarecimento. Entretanto, 68 anos depois do lançamento desse livro, poucos avanços foram feitos no sentido de aprofundar os problemas implícitos na crítica de "Frankfurt". Por um lado, na Europa, o pensamento crítico não sem razão ou motivo, fora varrido das universidades. Por outro, na América do Sul se tem uma miscelânea eclética de teorias que tentam abarcar os problemas dos "deserdados", mas que sempre é ineficaz diante das categorias contra as quais se debate. Talvez, os motivos dessa ineficiência estejam ligados às próprias muletas teóricas de que fazem uso, pois, tais 1 Mestre em Estética e Filosofia da Arte pela Universidade Federal de São Paulo (UNIFESP) e coordenador político da UNEAFRO. 
muletas não raras vezes são intrínsecas aos ideais do Esclarecimento ligados naturalmente aos mecanismos de defesa do capital.

A ideologia do Esclarecimento se tornou tão arraigada ao dia-a-dia comum que muitas vezes se tem uma naturalização de seus pressupostos. Isso dificulta uma reflexão crítica que investigue a gênese diretriz de seus princípios. Princípios que não foram criados do nada ou por uma consciência infeliz, mas, que estão ligados a forma como o homem branco e europeu desenvolveu-se na medida em que desenvolvia o moderno sistema produtor de mercadorias. O mito fornecido pela razão esclarecida tornou-se tão forte que mesmo ante o iminente colapso da civilização, os planejamentos estratégicos baseados nos cálculos são acatados sem crítica ou objeções se forem feitos por especialistas esclarecidos.

Por isso, a medida que o capital se desenvolveu, mais e mais a abstração da produção e reprodução social moldou a subjetividade moderna fundada na concorrência posta em prática pela economia. "A distância do sujeito com relação ao objeto, que é o pressuposto da abstração, está fundada na distância em relação à coisa, que o senhor conquista através do dominado" (ADORNO E HORKHEIMER, 2006, p.25). Essa distância apontada pelos críticos, entre as atividades teóricas e manuais, irá constituir a abstração que legitimará o modo de reprodução social. E é exatamente isso, que ergue os pressupostos do Esclarecimento coadunados com o desenvolvimento do capital e excludente daquilo que não está diretamente ligado ao processo de valorização. "O que não se submete ao critério da calculabilidade e da utilidade torna-se suspeito para o esclarecimento" (ADORNO E HORKHEIMER, 2006, p.19).

Não é por acaso que o propósito de crítica ao capitalismo, muitas vezes, esbarre nas categorias utilizadas para compreender as formas socioculturais engendradas pelo próprio capitalismo. Tais formas socioculturais muitas vezes são analisadas a partir do prisma do colonizador europeu e a crítica se furta a refletir radicalmente o seu conteúdo normativo ligado ao conceito de Esclarecimento. Tal problema da crítica se efetiva porque a ideologia do modo de produção e reprodução social, que se legitima no Esclarecimento, carrega em suas categorias uma suposta promessa emancipatória.

Foi Marx quem forneceu subterfúgios para uma crítica central à própria noção de modernidade e esclarecimento quando analisando a gênese do desenvolvimento do Capital descobriu um sujeito que subsume todos os outros a seu Império. Este é o sujeito-automático. Isto quer dizer que nessa sociedade o único sujeito é o em-si-para-si da moderna forma dominante de exploração, ou seja: O capital. Como pensou Krahl 
(1982, p.36): "Em primeiro lugar, sujeitando a crítica um quid pro quo, Marx determina o indivíduo burguês não como criatura biológica singular em sua estrutura animal, e sim como produto de relações da divisão social do trabalho altamente desenvolvidas, que exigem autonomia, maturidade e emancipação com respeito a natureza e suas coações. Em segundo lugar, Marx afirma que o conceito de sociedade no sentido rigoroso, vale somente para a sociedade burguesa".

É em última instância, o capital que se efetiva e torna-se o sujeito das relações agora objetificadas socialmente. O homem - mesmo o branco europeu - entra nela somente como mercadoria e, nesse sentido, em princípio o ex-escravo ou as mulheres não tem os "requisitos mínimos" para ser incluso na esfera da valorização do capital. Ora, não é mero acaso que ao ser abolida a escravidão aqui no Brasil, imediatamente se criou a política de imigração. Acompanhando o desenvolvimento do capitalismo, a ideologia do Esclarecimento referendou profundamente suas práticas justificando a exclusão com os ditos pensamentos científicos e higienistas.

Assim, o desenvolvimento da crítica esclarecida tornou estéril a crítica ao próprio Esclarecimento. Não era mais possível pensar um mundo para além do Esclarecimento e suas promessas de suposta emancipação e felicidade. "O conceito de felicidade, em si mesmo obscuro e arbitrário, jamais significou outra coisa senão o êxito junto à concorrência, o que sempre pressupõe os objetos da felicidade numa forma capitalista, para além da qual não deve haver nenhuma outra forma" (KURZ, 2010 p.45).

Assim, a forma da felicidade dentro do Esclarecimento é a forma da própria manutenção e impulso do capital. A felicidade passa, assim, pelo crivo da concorrência e disputa no mercado de trabalho, disputa que alija de antemão aqueles que não têm os requisitos mínimos ${ }^{2}$ para dela participar. Por isso, não se trata aqui de buscar efetivar o que a ideologia burguesa só tem como ideal, pelo contrário, seu próprio ideal já exclui de si todos os que não têm os "requisitos necessários". Para tê-los, com efeito, é necessário abandonar suas características e abraçar as características impostas pelo ideal burguês do Esclarecimento.

O negro adquire, dessa maneira, uma posição acessória com a mulher, se for negro e mulher o status social imposto pela modernidade diminui ainda mais. Isso porque "as formas de consciência são produzidas e suscitadas pelas fundamentais

2 Espero que entendam a franca ironia dessa frase. 
relações de divisão do trabalho, mas como estas relações são também elas abstratas por sua vez resultam condicionadas pela comunicação linguística" (KRAHL, 1982, p.39). Assim, é preciso entrar na desleal concorrência e sacrificar-se muito mais se adequando, em nome da inclusão, a esfera de valorização do capital no interior do mercado. Acatar esse código abstrato que impõe os comportamentos aceitáveis, torna-se a missão de qualquer negro que queira disputar uma vaga de emprego. No Brasil onde a suposta "democracia racial" até hoje é alardeada, mesmo com os sacrifícios impares, os negros ficam em segundo plano nas contratações. Florestan Fernandes mostrou isso com clareza atroz em seu A integração do negro na sociedade de classes, de lá para cá, como mostram os dados dos diversos sensos, essa realidade não mudou.

Por isso, a tarefa da crítica deve ser efetivada com a responsabilidade de denunciar o caráter destrutivo e excludente do próprio ideal burguês. Suas categorias de universalidade, igualdade, felicidade ou liberdade estão todas imiscuídas na forma de dominação capitalista e são, por isso, contrários a uma emancipação efetiva da humanidade. A igualdade abstrata refere-se exclusivamente ao universo da valorização e manutenção do capital, e para que seja válida aos negros estes tem que atuar no interior dessa dinâmica.

A universalidade abstrata enquanto ideal, e destrutiva na sua relação concreta de exploração, exclui de si o próprio indivíduo - branco ou preto - que precisa resolver-se, se alienando na produção e reprodução da vida sob a égide do capital. O que constitui esse indivíduo é a própria condição de cisão, por isso, a universalidade do Esclarecimento burguês baseia-se nessa relação cindida. Cisão efetivada entre objetividade e subjetividade, entre trabalho manual e espiritual, entre homens e mulheres, entre brancos e pretos, entre hetero e homo e entre o indivíduo trabalhadorconsumista e indivíduo desempregado-não humano. Assim, a cisão moderna constitui o mundo social e a universalidade patriarcal abstrata do Esclarecimento que impulsiona o capital.

O universalismo proposto pelo Esclarecimento advém então das relações que efetivam o capital e, é por isso que baseado na concorrência constitui um mecanismo de exclusão. Exclui todos aqueles que não podem adentrar e manter o automovimento do sujeito automático. Hierarquiza e torna supérfluos aqueles que não se adéquam ao modelo proposto por essa mesma universalidade, universalidade do homem branco, europeizado e patriarca. Não é a toa que em momentos de refluxos do crescimento destrutivo do capital, como os que estamos vivendo hoje, os primeiros a serem postos 
no desemprego são as mulheres e os negros. Por isso, o racismo, ao contrário do que se acreditava, constitui a delimitação dessa universalidade ideal burguesa que é inerente à concorrência no mercado de trabalho.

Desse modo, a luta inclusiva pelo acesso do negro esbarra nas próprias categorias que erguem o mundo concreto e excludente do qual critica. A inclusão não apenas, não resolve a cisão imposta pela forma de produção e reprodução capitalista, como tampouco refuta o Universalismo Esclarecido como relação social de exclusão racista. As melhorias propostas pela inclusão giram em torno da própria dinamização da valorização do capitalismo e da sua universalidade racista, xenófoba, homofóbica e machista. O Esclarecimento, portanto, não apenas é a forma de atuação e legitimação ideológica do colonizador branco e patriarcal, como ainda constitui a principal forma de manutenção do sistema excludente que chamamos de capitalismo.

É preciso lembrar com Florestan Fernandes (1959, p. 221) que "o que importa assinalar é que não ocorreu um esforço criativo para engendrar uma teoria revolucionária adaptada a essas condições de eclosão histórica do período de transição, que propusesse as contradições emergentes e a política para enfrentá-las". O único adendo que faríamos aqui é que tal teoria provavelmente não possa emergir dos pressupostos do esclarecimento. Esse motivo talvez explique o fato de os ditos "socialismos reais" terem mantido as mesmas formas de exploração capitalista e os mesmos critérios de exclusão, xenofobia, homofobia e machismo. Razões estas que, no mundo globalizado e informado de hoje, faz vítima um pai que é derrubado pela rasteira de uma jornalista do esclarecimento.

Palavras-chave: negros - racismo - esclarecimento - modernidade - capital 


\section{BIBLIOGRAFIA.}

ADORNO e HORKHEIMER. Dialética do Esclarecimento. Rio de Janeiro: Jorge Zahar, 2006.

FERNANDES, F. Da guerrilha ao socialismo: a revolução cubana. São Paulo: T.A Queiroz. 1979.

HEGEL, G.W.F. Fenomenologia do Espírito. São Paulo: Vozes, 2012.

KRAHL, H. J. Introdução de 1857 de Marx. In: MARX, K. Introdução a crítica da economia política. Barcelona: Contrafuegos, 1969.

KURZ, R. Razão sangrenta: ensaios sobre a crítica emancipatória da modernidade capitalista e seus valores ocidentais. São Paulo: Hedra, 2010.

KARL MARX. O Capital, Livro I, vl. I. Rio de Janeiro: civilização brasileira, 2008. O Capital, Livro I, vl. II. Rio de Janeiro: Civilização brasileira, 2008. 